\title{
Solar Assisted Gasification of Solid Feedstock: Optical Arrangement and Numerical Simulation
}

\author{
Syed Shabbar Raza, Isam Janajreh* \\ Masdar Institute of Science and Technology, Abu Dhabi, UAE
}

\begin{abstract}
Gasification is a high temperature thermo-chemical pathway that is used to convert a solid fuel/feedstock into combustible syngas $\left(\mathrm{CO}\right.$ and $\left.\mathrm{H}_{2}\right)$ and chemicals. The gasified species derive their formation energy by combusting 20 $30 \%$ of the feedstock. The combustion resulted in emission of soot, particulate matter, NOx and SOx. Therefore, an attempt is made in this work to offset the energy required for gasification through the use of concentrated solar power, i.e. solar to enthalpy. The system consists of a parabolic and hyperbolic reflector using Cassegrain configuration to concentrate $5 \mathrm{~kW}$ of solar flux for the gasifier. Furthermore, a high fidelity computational fluid dynamics (CFD) simulation is established based on the results of thermodynamic and optical models. The CFD simulation couples the effect of heat transfer through solar radiation and reaction kinetics in the participating media. The results demonstrate a cold gasification efficiency of $90 \%$ with the product mole fraction of $\mathrm{CO}$ and $\mathrm{H}_{2}$ of 0.22 and 0.32 , respectively, thereby suggesting the viability and large scale implementation of the system.
\end{abstract}

Keywords: solar assisted gasification, cassegrain configuration, solar to chemical

\section{Introduction}

The fast growing industrialization across the globe put imminent call to generate energy in efficient and much clearer way. The burning of fossil fuel during last two centuries provides the energy demand of the world but on other hand it substantially continue to increase the environmental pollution. The environmental problem is not only in the form of greenhouse gas (GHG) emission, but also the solid residues that contaminate the ground water resources. Also, the major portion of GHG is produced by the combustion of fossil fuel in the power plants which require an additional cost to capture then to store or sequestering it [1].

Therefore it is needed to work on the technologies that can negate the burden on environment which were create during last two centuries or at least not to increase further. Although, immediate shifting toward clean technologies may not possible, embracing intermediate pathways and technologies is needed to bridge this gap. Gasification is one of the thermo chemical pathway that can be used to generate cleaner fuel.
Using this technology any carbonaceous fuel (fossil fuel, coal, natural gas, biomass) can be converted into syngas $\left(\mathrm{CO} \& \mathrm{H}_{2}\right)$.

Gasification in integrated gasification combined cycle (IGCC) is promoted as cleaner and more efficient energy conversion method than the conventional pulverized coal steam cycle [2]. Gasification is an endothermic process which occurs at high temperature range $\left(>1000^{\circ} \mathrm{C}\right)$. The main product of gasification is $\mathrm{H}_{2}$ and $\mathrm{CO}$ gases, which can be used in fuel cell or in IGCC to generate electricity. Details of the gasification process are complex, nevertheless, the process entails drying, evaporation, devolatilization, pyrolysis and combustion with the presence of oxidizer. Due to the endothermic nature of gasification it requires a considerable amount of energy to sustain the process. Conventionally, around $30 \%$ of feedstock energy is consumed to provide the required process sensible heat. A major drawback of combustion is that its byproduct, in the form of soot and NOx and SOx, contaminates the product syngas, which requires an additional resource to be separated from the product gaseous mixture. Using the solar energy to provide the sensible heat to process can avoid the problem associated with conventional gasification. The partial combustion of feedstock for auto-thermal gasification will no

* Corresponding author. Tel.: +97128109130

E-mail: ijanajreh@masdar.ac.ae

(C) 2014 International Association for Sharing Knowledge and Sustainability

DOI: $10.5383 /$ ijtee.07.02.002 
longer required when using solar energy, therefore, the product syngas from gasifier is not contaminated by the byproduct of partial combustion of feedstock. The $30 \%$ of feedstock required for combustion along with the stoichiometric amount of oxidizer is saved. The calorific value or heat of reaction of product gas will be increase by an amount equal to the solar energy added in the reactor. The high temperature as the result of solar radiation without burning the feedstock results in good quality syngas as the nature of reaction is endothermic. Also, substantial emission of $\mathrm{CO}_{2}$ can be avoided.

Progress to use the concentrated solar radiation to convert feedstock into fuel is an active research area. Zedtwintz et.al [3-5] has used both, experimental and simulation approaches to investigate the steam-gasification of coal using concentrated solar radiation. Initially a thermodynamics equilibrium approach is used to model the process. System integration and its efficiency was calculated by considering three different viable routes for coal gasification.

Piatkowski et al. [6] has investigated solar-chemical gasification of waste carbonaceous feedstock for high quality syngas. The reactor is modelled using combined heat transfer coupled to reaction kinetics, driven by the applied solar flux. In subsequent work [7], they discussed the kinetics mechanism of steam gasification to provide more fundamental understanding of the process chemistry.

Graggen et al. [8-10] has conducted a series of experiment to simulate the solar gasifier. Initially the reactor is designed and then tested. The result of syngas from the experiment was reasonably compared with the modelled result. Also, the system efficiency is calculated.

Pitz [11, 12] has modelled an optimization algorithm for an optical configuration to concentrate the solar radiation. The configuration of a heliostat field is designed to use for coal gasification. Also, they conducted study for the economic feasibility of the optical arrangement.

The research shows the viability of the gasification process through solar energy. It shows that the gasification process can be enhancing by increasing the process temperature without combusting the feedstock to produce good quality syngas. This can be done by providing process endothermic heat requirement by virtue of solar energy. Therefore, in the presence study the concept of solar assisted gasification is promoted by conducting an integrating optical and CFD simulation. Initially an optical configuration is designed to concentrate the solar radiation. The result of optical configuration is used to conduct the numerical study of solarsteam gasification. The results are presented in both quantitative and qualitative form that also show the process efficiency.

\section{Solar radiation modeling}

Cassegrain configuration is a known arrangement of a parabolic and a hyperbolic reflector for the solar flux concentration. The main advantage of this configuration is a high concentration ratio with an inline focal direction to the solar radiation. The basic Cassegrain configuration is given in Fig.1.

An attempt is made to model the Cassegrain configuration following Ray tracing method to simulate the radiation and via the TracePro software [13]. The primary model is shown in Fig. 2. The Sun is modelled as a surface emitting the radiation with flux of $1000 \mathrm{w} / \mathrm{m} 2$. The solar flux is incident on the parabolic dish, in line with it focal length. Another view of solar source, parabolic and hyperbolic reflector is shown in
Fig. 3, showing the model without rays. The solar radiations are modelled by defining a surface. The radiations are emitting from the surface in the perpendicular direction. The parabolic dish is aligned so that the incoming radiations are in line with the focal length. Similarly, the focal length of hyperbolic reflector is in line with that of parabolic dish. In this way, the solar radiations are concentrated in the direction of radiation coming from the sun source.

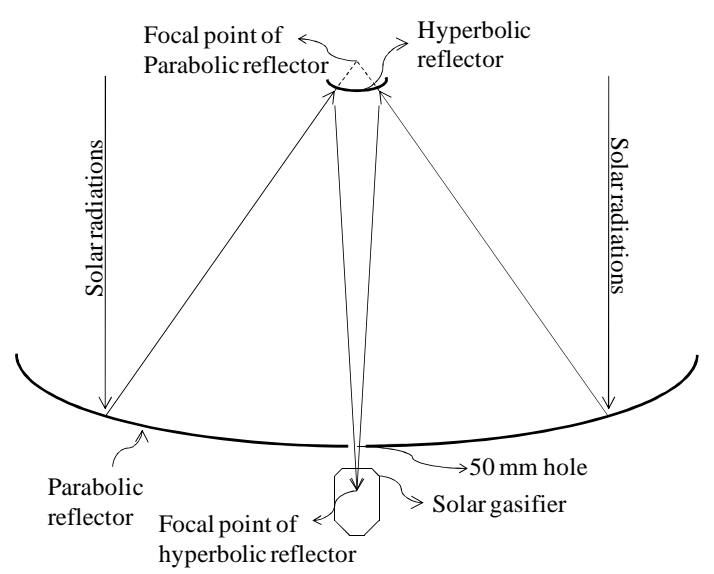

Fig.1: Cassegrain configuration for concentrating solar irradiation

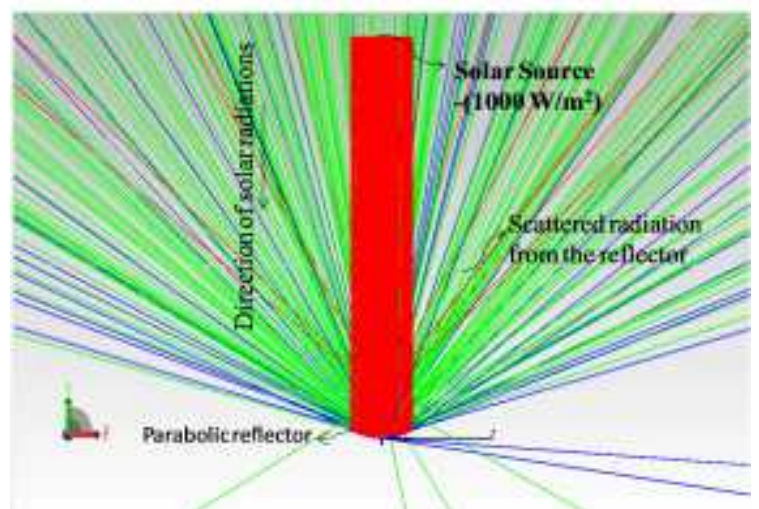

Fig. 2: Cassegrain configuration modeling

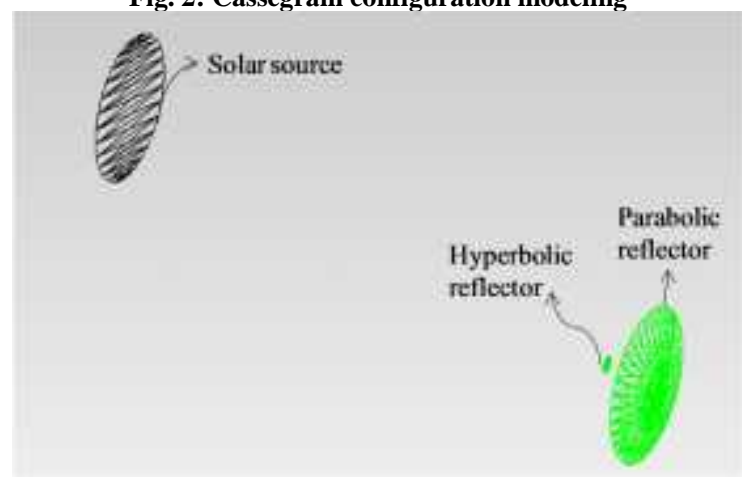

Fig. 3: Plane view of Cassegrain configuration with solar source

The design parameters of parabolic and hyperbolic reflector are given in

Table 1. The thickness of the material is taken as $5 \mathrm{~mm}$. Although, the thickness does not affect the reflectivity of material but it is used to calculate the surface temperature of the reflector when solar flux is absorbed. The radius of hole presents at the center of parabolic dish is design at $50 \mathrm{~mm}$ that allows a clean passage for all the incoming flux from hyperbolic dish. The focal length is designed at $1500 \mathrm{~mm}$ so that it can accommodate the distance of parabolic reflector to the hyperbolic reflector; also the focal length of hyperbolic 
reflector is kept in consideration while designing for the focal length of parabolic dish. The overall reflectivity of parabolic dish and hyperbolic reflector is taken as 0.95 [9], i.e. same reflectivity of the central receiver installed at Masdar city beam down solar plant. The solar gasfier have the height of $210 \mathrm{~mm}$ with $50 \mathrm{~mm}$ of diameter. The optical window is considered as transparent with diameter of $25 \mathrm{~mm}$. The reflectivity of wall of solar gasifier is taken to be 0.5 , which is typical for the refectory material.

Table 1: Design parameters for parabolic and hyperbolic reflector

\begin{tabular}{|l|c|l|c|}
\hline \multicolumn{2}{|c|}{ Parabolic reflector } & \multicolumn{2}{c|}{ Hyperbolic reflector } \\
\hline Thickness & $5 \mathrm{~mm}$ & Thickness & $5 \mathrm{~mm}$ \\
\hline Hole radius & $50 \mathrm{~mm}$ & Front focal length & $100 \mathrm{~mm}$ \\
\hline Focal Length & $1500 \mathrm{~mm}$ & Back focal length & $1400 \mathrm{~mm}$ \\
\hline Length & $326.67 \mathrm{~mm}$ & Length & $50 \mathrm{~mm}$ \\
\hline Reflectivity & 0.95 & Reflectivity & 0.95 \\
\hline
\end{tabular}

\section{Numerical simulation}

The basic geometry of solar gasifier is taken from literature [8]. It consists of a cylindrical cavity receiver of $210 \mathrm{~mm}$ length having inside diameter of $100 \mathrm{~mm}$ with an optical opening of $50 \mathrm{~mm}$ at one end of cylinder for the radiation aperture. The computational model for gasifier cavity is shown in Fig. 4. The model is generated using two dimensional (2D) axis-symmetric boundary condition which allows the feature of a three dimensional (3D) geometry in two 2D- domain. The temperature of the steam/moderator is introduced at $423 \mathrm{~K}$ though inlet with mass flow rate of $1.005 \mathrm{E}-4 \mathrm{~kg} / \mathrm{s}$. The temperature of the coal particles are introduced at $300 \mathrm{~K}$ through injector with mean particle diameter of $1.42 \mathrm{~m}$ and mass flow rate of $3.6 \mathrm{E}-5 \mathrm{~kg} / \mathrm{s}$. A heat flux equivalent to $662 \mathrm{~W}$ is applied to the optical window to simulate the incoming solar flux. The heat flux is applied after deducting the effect of heat losses by means of re-radiation from the optical window and conduction/convection through reactor wall. Operating conditions are also summarized in Table 2 .

Table 2: summary of operating conditions

\begin{tabular}{|l|l|}
\hline Parameter & Value \\
\hline $\mathrm{m}_{\text {Steam-inlet }}$ & $1.005 \mathrm{E}-4 \mathrm{~kg} / \mathrm{s}$ \\
\hline $\mathrm{m}_{\text {coal-inet }}$ & $3.6 \mathrm{E}-5 \mathrm{~kg} / \mathrm{s}$ \\
\hline $\mathrm{T}_{\text {steam-inlet }}$ & $423 \mathrm{~K}$ \\
\hline $\mathrm{T}_{\text {coal-inlet }}$ & $300 \mathrm{~K}$ \\
\hline $\mathrm{D}_{\text {Coal }}$ & $1.42 \mathrm{~m}$ \\
\hline $\mathrm{Q}_{\text {solar-effective }}$ & $662 \mathrm{~W}$ \\
\hline
\end{tabular}

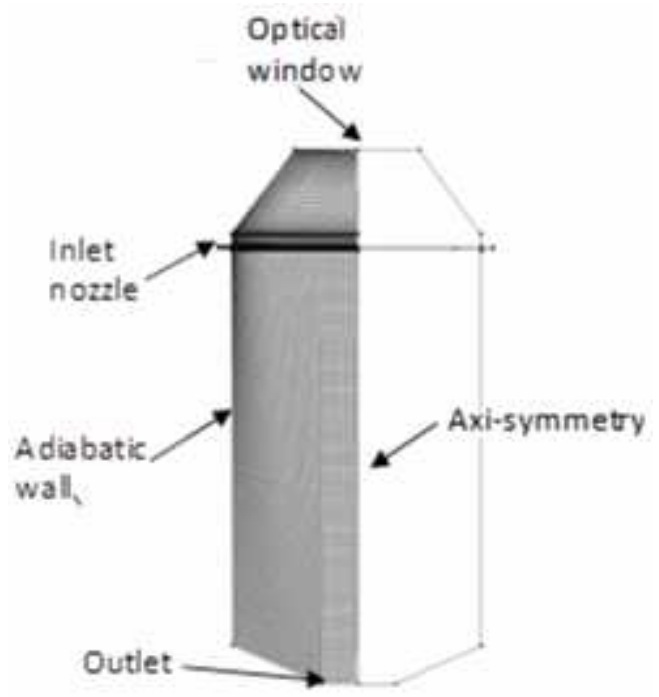

Fig. 4: Computational model for solar gasifier

Modeling of solar assisted gasification involves the application of conservative laws, and tracking of species and accounting for volatile evolution, char particles burnout, and coupling the homogeneous chemistry occurring in the gas phase. It requires simultaneous resolution of the conservative laws (mass, momentum, energy and radiative transfer equation) and scalar transport equations of the species and their turbulence kinetic energy and dissipation rate. It is a two phase flow regime one representing the continuous gaseous phase which is coupled with the second dispersed solid particle/coal phase. The continuous phase is governed by the following generic equation form:

$\frac{\partial}{\partial t}(\phi)+\frac{\partial}{\partial x_{i}}\left(u_{i} \phi\right)=-\frac{\partial}{\partial x_{i}}\left(\Gamma_{\phi} \frac{\partial \phi}{\partial x_{i}}\right)+S_{\phi}$

\section{Time rate advective diffusion source}

Where $u_{i}$ is the velocity and $S_{\phi}$ is a source terms due to the dispersed/discrete phase interaction. $\phi$ is the dependent variable correspond to the density $(\rho)$, the density-velocity multiple $\left(\rho u_{i}\right)$, and the temperature $(T)$ representing the conservation of mass, momentum, and energy, respectively. $\phi$ can represent also turbulent scalars, i.e. turbulent kinetic energy $(k)$ and the turbulent dissipation rate $(k)$. These two equations in a steady state flow regime are written as:

$$
\begin{aligned}
& \rho u_{i} \frac{\partial k}{\partial x_{i}}=\mu_{t}\left(\frac{\partial u_{j}}{\partial x_{i}}+\frac{\partial u_{i}}{\partial x_{j}}\right) \frac{\partial u_{j}}{\partial x_{i}}+-\frac{\partial}{\partial x_{i}}\left(\frac{\mu_{t}}{\sigma_{k}} \frac{\partial k}{\partial x_{i}}\right)-\rho \varepsilon \\
& \rho u_{i} \frac{\partial \varepsilon}{\partial x_{i}}=C_{1 \varepsilon} \frac{\mu_{t} \varepsilon}{k}\left(\frac{\partial u_{j}}{\partial x_{i}}+\frac{\partial u_{i}}{\partial x_{j}}\right) \frac{\partial u_{j}}{\partial x_{i}}+\frac{\partial}{\partial x_{i}}\left(\frac{\mu_{t}}{\sigma_{\varepsilon}} \frac{\partial \varepsilon}{\partial x_{i}}\right)-C_{2 \varepsilon} \frac{\rho \varepsilon^{2}}{k}
\end{aligned}
$$

The right hand terms are representing the generation, the diffusion, and destruction, respectively. In these equations, $\mu_{\mathrm{t}}$ is the turbulent or eddy viscosity which overwhelms the laminar viscosity, and is equal $\mu_{t}=f_{\mu} C_{\mu} \rho k^{2} / \varepsilon$. Where $f$ and $C$ are constants and $C_{l \varepsilon}, \mathrm{C}_{1 \varepsilon}, \sigma_{\kappa}$, and $\sigma_{\varepsilon}$, are empirical constants. Following equation 1 , the transportation of species $m_{i}$ is written as:

$\frac{\partial}{\partial t}\left(\rho m_{i}\right)+\frac{\partial}{\partial x_{i}}\left(\rho u_{i} m_{i}\right)=\frac{\partial}{\partial x_{i}}\left(\rho D_{i, m}+\mu_{t} / S c_{t}\right) \frac{\partial m_{i}}{\partial x_{i}}+R_{i}+S_{i}(3)$

Where $D_{i, m}$ is the diffusion coefficient of $m_{i}$ specie. $S c_{t}$ is the turbulent Schmidt number which is the ratio of the eddy viscosity $\mu_{t}$ to the eddy diffusivity $D_{i, m}$. These transport 
equations are incorporating an additional reaction source term $R_{i}$ that accounts for the species reaction and is governed by the stoichiometric reaction below:

$\sum_{i=1}^{N} v_{i, r}^{\prime} S_{i} \stackrel{k_{f, r}}{\Leftrightarrow} \sum_{k_{b, r}}^{N} \sum_{i=1}^{N} v_{i, r}^{\prime \prime} S_{i}$

The reaction rate is proportional to the reaction's products raised to power coefficient that indicates their concentration independency. That is, the $i^{\text {th }}$ species production/destruction due to the reaction $r$ is written as:

$$
R_{i, r}=M_{i, r}\left(v_{i, r}^{\prime \prime}-v_{i, r}^{\prime}\right)\left(k_{f} \prod_{j=1}^{N} C_{j, r}^{\eta_{j, j}^{*}}-k_{r} \prod_{j=1}^{N} C_{j, r}^{\eta_{j}^{*}, r}\right)
$$

where $k_{f}$ and $k_{r}$ are the forward and backward reaction constants based on Arrhenius equation, $C_{j}$ is the molar concentration of the $j^{\text {th }}$ specie raised to stoichiomtric coefficients $v$ and reaction order $\eta$, and $M_{i}$ is the molecular weight of species $i$.

For the solid phase, the discrete Lagrangian method is used and considering the small particle volume fraction, one-way coupling is assumed. The discrete second phase is solved in a Lagrangian frame of reference which consists of the spherical particles dispersed in the continuous phase. Their trajectory is predicted by integrating the force balance on the particle. This force balance equates the particle inertia with the forces acting on the particle and can be described as:

$\frac{d \vec{u}_{P}}{d t}=F_{D}\left(\vec{u}-\vec{u}_{P}\right)+\vec{g}\left(\rho_{P}-\rho\right) / \rho_{P}+\vec{F}$

Where $F_{D}\left(u-u_{p}\right)$ is the drag force per unit particle mass; $u$ is the fluid phase velocity; $u_{p}$ is the particle velocity; $\rho$ is the fluid density, and $\rho_{p}$ is the density of the particle. The trajectory equations are solved by stepwise integration over discrete time steps. Integration in time of Eq. (6) yields the velocity of the particle at each point along the trajectory, where the trajectory itself is predicted by the following equation:

$$
\frac{d x}{d t}=u_{P}
$$

Equations similar to (6) and (7) are solved for each coordinate direction to predict the trajectories of the discrete phase. The trajectories of the discrete phase particles are computed as well as the heat and mass transfer to and from them. Inert heating law is applied while the particle temperature is less than the vaporization temperature. Devolatilization law is applied to the combusting particle when the temperature of the particle reaches the vaporization temperature, $\mathrm{T}_{\text {vap. }}$. It is written as:

$-\frac{d m_{p}}{d t}=A e^{-(E / R T)}\left[m_{p}-\left(1-f_{v}^{0}\right) m_{p}^{0}\right]$

Where $m_{p}$ is the particle mass and $f_{v}$ is the volatile mass fraction.

It remains in effect while the mass of the particle exceeds the mass of the non-volatiles in the particle. The heat transfer to the particle during the devolatilization process governs the contributions from convection, radiation, and the heat consumed during devolatilization. It is written as:

$m_{p} c_{p} \frac{d T_{p}}{d t}=h A_{p}\left(T_{\infty}-T_{p}\right)+\frac{d m_{p}}{d t} h_{f g}+\varepsilon_{p} A_{p} \sigma\left(T_{R}^{4}-T_{p}^{4}\right)$

After the volatile component of the particle is completely evolved, a surface reaction begins, which consumes the combustible fraction of the particle until the combustible fraction is consumed. Heat, momentum, and mass transfer between the solid fuel particles and the gas will be included by alternately computing the discrete phase trajectories and the continuous phase equations.

Heat transfer for radiation is modeled using discrete ordinates (DO) method. It solves the radiative transfer equation for a finite number of discrete angles for the solid body, i.e. particle or refractory, associated with a vector direction $S$ fixed in the global Cartesian system (x, y, and z), it can be written as;

$\nabla .(I(\vec{r}, \vec{s}) \vec{s})+\left(a+\sigma_{S}\right) I(\vec{r}, \vec{s})=a n^{2} \frac{\sigma T^{4}}{\pi} \int_{0}^{4 \pi} I(\vec{r}, \vec{s}) \Phi(\vec{s} . \vec{s}) d \Omega$

DO model transform the radiation heat transfer equation into transport equation for radiation intensity.

\section{Solution procedure}

The finite volume method was used to solve the governing equations. The procedure for the calculation of pulverized feedstock combustion is (a) Solve the continuous phase flow field prior to the introduction of the discrete phase equations; (b) Introduce the discrete phase by calculating the particle trajectories for each discrete phase injection; (c) Recalculate the continuous phase flow, using the inter-phase exchange of momentum, heat, and mass determined during the previous particle calculation; (d) Recalculate the discrete phase trajectories in the modified continuous phase flow field; (e) Repeat the previous two steps until a convergence solution is achieved in which both the continuous phase flow field and the discrete phase particle trajectories are unchanged with each additional calculation.

\section{Results and discussion}

The solar flux is simulated for the optical configuration defined in the preceding discussion. The results are gathered in both qualitative and quantitative formats. Fig. 5 provides the flux distribution over parabolic reflector. The flux distribution is modelled using the probabilistic distribution of 1004 incident rays. The maximum flux of $4,087 \mathrm{w} / \mathrm{m}^{2}$ is measured and the total 5,563 watts are recorded over the entire surface. Similarly, Fig. 6 shows the flux distribution over hyperbolic reflector. Total of 1,009 rays strike the wall of hyperbolic reflector that creates a maximum flux of $4.31 \times 10^{5} \mathrm{w} / \mathrm{m}^{2}$. The total of $5,360 \mathrm{~W}$ is measured on the surface of hyperbolic reflector.

The concentrated radiation from the hyperbolic reflector pass though the center hole of parabolic dish and enter into the solar gasifier via transparent optical window. Fig. 7 shows the flux distribution inside the solar gasifier that lies beneath the parabolic dish. The radiation flux, after entering the solar gasifier through transparent optical window, reflected several times from the wall. Some of the radiation gets escaped from the optical window. The multiple internal reflections increase the radiation to absorb more. 


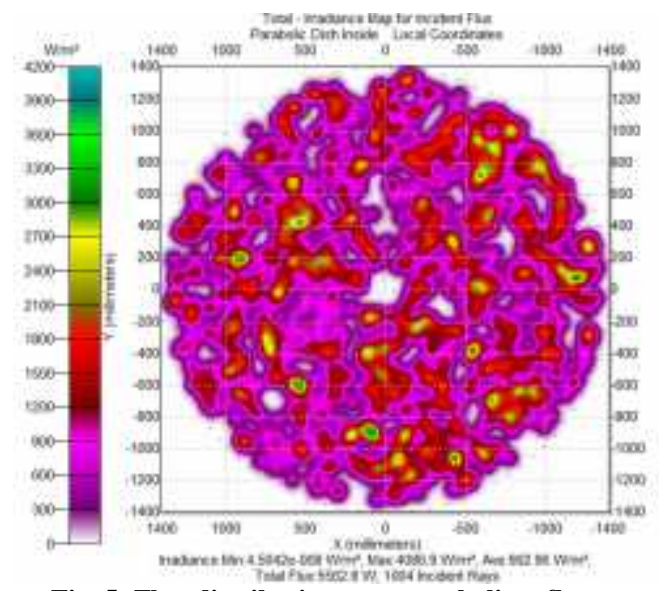

Fig. 5: Flux distribution over parabolic reflector

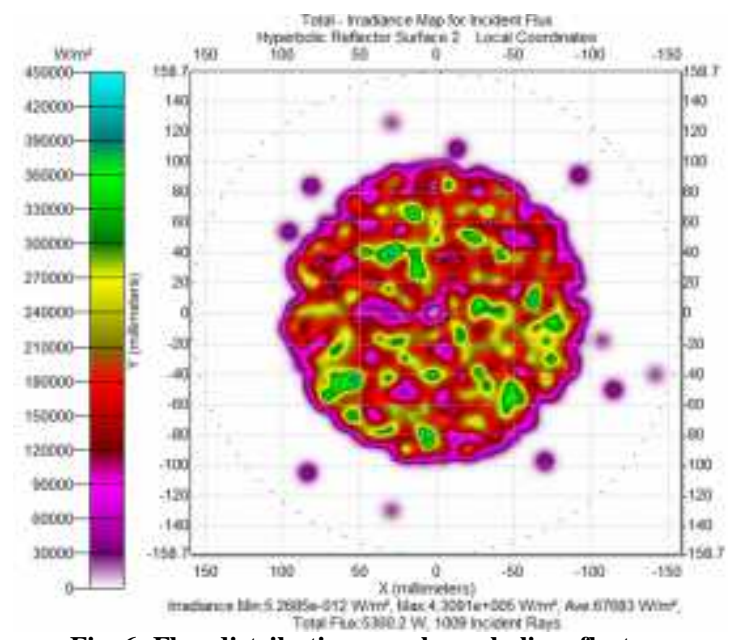

Fig. 6: Flux distribution over hyperbolic reflector

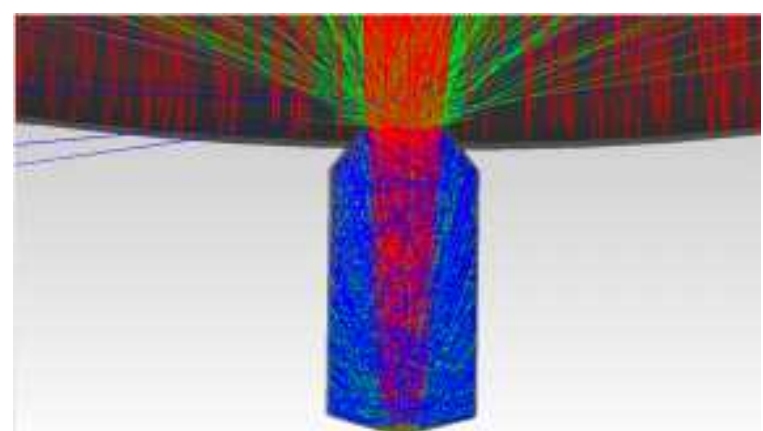

Fig. 7: The qualitative result of flux distribution for solar gasifier

Table 4. Prior of conducting high fidelity CFD simulation a stoichiometric equilibrium computation following our previous work [14] has been carried out. The RTC coal, Kentucky bitominus grade, has been used where proximate and ultimate
The quantitative results for the simulation are presented in Table 3. It is evident that the area of parabolic dish is much higher as compared to the surface area of solar gasifier and hyperbolic reflector. The total incident flux on parabolic reflector is calculated to be 5,620 Watts, out of that 184 Watts is absorbed by the reflector and 157 Watts are lost by rays scattering. Similarly, the hyperbolic receive 5,503 Watts from the parabolic dish. It means that 117 Watts are lost when the ray reflected from parabolic dish to hyperbolic reflector. The hyperbolic reflector absorbs 134 Watts of energy and 213 Watts lost due to scattering. The total flux incidents on the walls of solar gasifier are measured to be 8,389 Watts. The total radiative energy leaving the surface of hyperbolic reflector is much less than 8,389 Watts. But, due to multiple internal reflections inside the solar gasifier it creates a black body cavity effect. The total flux absorbed by the walls of solar gasifier is measured to 4,103 Watts. A considerable amount of flux is re-radiated back from the optical window and it is calculated to be 727 Watts. In the work of Graggen [9], the solar radiation is taken as 4,488 watts which is in close proximity with the flux reflected from the hyperbolic reflector i.e. 5,503-134-213=5,156 Watts. Their re-radiation losses from the optical window was also found 575 Watts and that is also close to the results calculated in this simulation i.e. 727 Watts. The difference between the re-radiation value may due to the application of vacuum conditions inside the reactor in the simulation, Graggen et al however used the concept of participating medium comprised of solid and gaseous phase.

\begin{tabular}{|c|c|c|c|c|}
\hline Surface & $\begin{array}{l}\text { Surface } \\
\text { Area } \\
\left(\mathrm{mm}^{2}\right)\end{array}$ & $\begin{array}{l}\text { Incident } \\
\text { Flux } \\
\text { (Watts) }\end{array}$ & $\begin{array}{c}\text { Absorbed } \\
\text { Flux } \\
\text { (Watts) }\end{array}$ & $\begin{array}{l}\text { Lost } \\
\text { Flux } \\
\text { (Watts) }\end{array}$ \\
\hline Solar Gasifier & 144,319 & 8,386 & 4,193 & 727 \\
\hline Parabolic reflector & $131,67,983$ & 5,620 & 184 & 157 \\
\hline $\begin{array}{l}\text { hyperbolic } \\
\text { reflector }\end{array}$ & 174,057 & 5,503 & 134 & 213 \\
\hline
\end{tabular}

A summary of the reaction and their kinetics constants is presented

analyses as well as clorific value and its inferred unit molecular formula is present in literature [14] following previous work of the authors [15].

Table 4: Summary of reaction kinetics 


\begin{tabular}{|l|l|l|l|l|}
\hline Reaction & $A$ & $\beta$ & $E_{a}$ & reaction order \\
\hline $\mathrm{CH}_{4}+1.5 \mathrm{O}_{2} \rightarrow \mathrm{CO}+2 \mathrm{H}_{2} \mathrm{O}$ & $5.028 \mathrm{E}+11$ & 0 & $2.001 \mathrm{E}+08$ & {$\left[\mathrm{CH}_{4}\right]^{0.7}\left[\mathrm{O}_{2}\right]^{0.8}$} \\
\hline $\mathrm{CO}+0.5 \mathrm{O}_{2} \rightarrow \mathrm{CO}_{2}$ & $2.238 \mathrm{E}+12$ & 0 & $1.704 \mathrm{E}+08$ & {$[\mathrm{CO}]\left[\mathrm{O}_{2}\right]^{0.25}\left[\mathrm{H}_{2} \mathrm{O}^{0.5}\right.$} \\
\hline $\mathrm{CO}_{2} \rightarrow \mathrm{CO}+0.5 \mathrm{O}_{2}$ & $8.891 \mathrm{E}+07$ & 0 & $1.704 \mathrm{E}+08$ & {$\left[\mathrm{CO}_{2}\right]$} \\
\hline $\mathrm{CH}_{4}+0.5 \mathrm{O}_{2} \rightarrow \mathrm{CO}+2 \mathrm{H}_{2}$ & $4.398 \mathrm{E}+11$ & 0 & $1.256 \mathrm{E}+08$ & {$\left[\mathrm{CH}_{4}\right]^{0.5}\left[\mathrm{O}_{2}\right]^{1.25}$} \\
\hline $\mathrm{CH}_{4}+\mathrm{H}_{2} \mathrm{O} \rightarrow \mathrm{CO}+3 \mathrm{H}_{2}$ & $3.000 \mathrm{E}+08$ & 0 & $1.256 \mathrm{E}+08$ & {$\left[\mathrm{CH}_{4}\right]\left[\mathrm{H}_{2} \mathrm{O}\right]$} \\
\hline $\mathrm{H}_{2}+0.5 \mathrm{O}_{2} \rightarrow \mathrm{H}_{2} \mathrm{O}$ & $6.800 \mathrm{E}+15$ & -1 & $1.675 \mathrm{E}+08$ & {$\left[\mathrm{H}_{2}\right]^{0.25}\left[\mathrm{O}_{2}\right]^{1.5}$} \\
\hline $\mathrm{H}_{2} \mathrm{O} \rightarrow \mathrm{H}_{2}+0.5 \mathrm{O}_{2}$ & $1.256 \mathrm{E}+17$ & -0.877 & $4.100 \mathrm{E}+08$ & {$\left[\mathrm{H}_{2}\right]^{-0.75}\left[\mathrm{O}_{2}\right]\left[\mathrm{H}_{2} \mathrm{O}\right]$} \\
\hline $\mathrm{CO}+\mathrm{H}_{2} \mathrm{O} \rightarrow \mathrm{CO}_{2}+\mathrm{H}_{2}$ & $2.750 \mathrm{E}+09$ & 0 & $8.374 \mathrm{E}+07$ & {$\left[\mathrm{CO}_{[}\left[\mathrm{H}_{2} \mathrm{O}\right]\right.$} \\
\hline $\mathrm{CO}_{2}+\mathrm{H}_{2} \rightarrow \mathrm{CO}+\mathrm{H}_{2} \mathrm{O}$ & $2.650 \mathrm{E}-02$ & 0 & $3.960 \mathrm{E}+03$ & $\left.\left[\mathrm{CO}_{2}\right] \mathrm{H}_{2}\right]$ \\
\hline
\end{tabular}

As for the CFD, the coal particles enter in the reactor at $300 \mathrm{~K}$ temperature and immediately exposed to high flux solar radiation. The high solar irradiation coming from optical window interacts with the reactor wall as well as the participating media, eventually the temperature of the reactor increase, as shown in Fig. 8. The maximum achievable radiation temperature is found in region around the optical window which gradually decreases towards the outlet. The radiation temperature is sufficiently high enough to provide appropriate heat for endothermic gasification reactions of steam and coal inside the gasifier. The mixture of steam and coal enters the gasifer through inlet nozzle with uniform velocity of $0.5603 \mathrm{~m} / \mathrm{s}$. The steam, carrying the coal particle, expands as its leaves the nozzle. The sudden expansion decreases the velocity of steam and the coal particle in the gasifier, as shown in Fig. 9, is provided with a sufficient residence time.

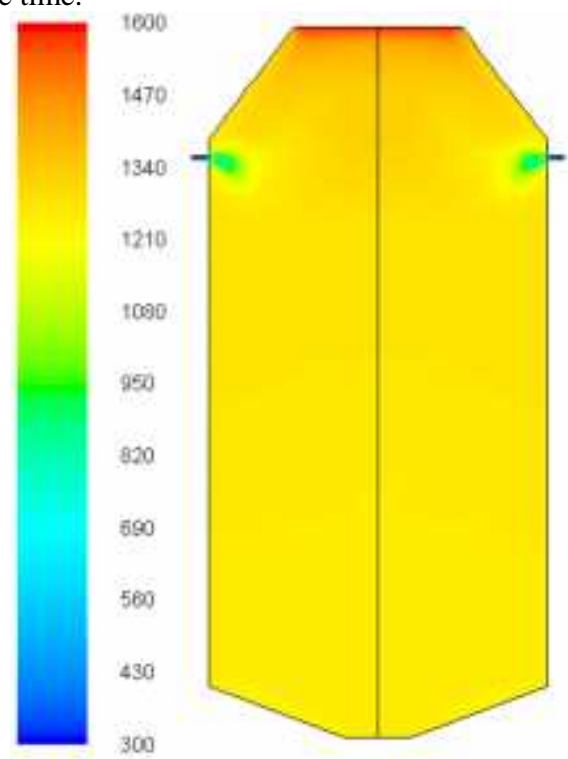

Fig. 8: Contours of temperature (K)

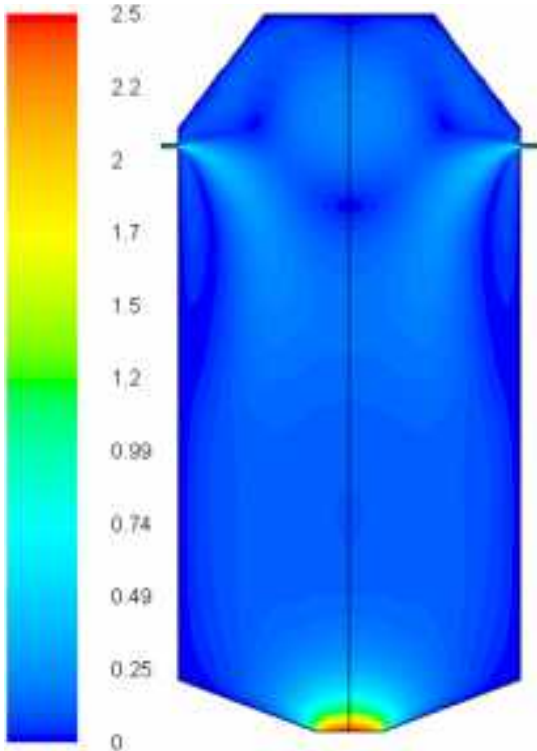

Fig. 9: Contours of velocity magnitude $(\mathrm{m} / \mathrm{s})$

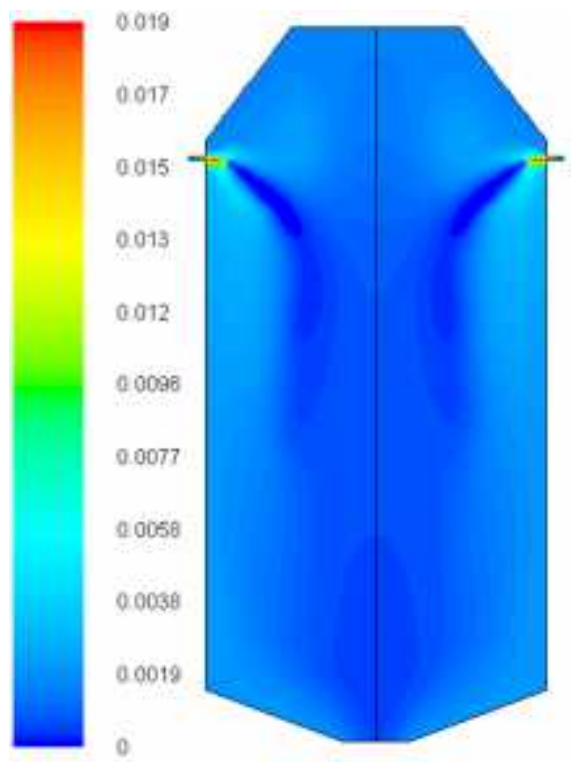

Fig. 10: Mole fraction of volatile contents

As the temperature of coal particle reaches at $400 \mathrm{~K}$ the particle starts to devolatilize by releasing light hydro-carbon which breaks up into components by reacting with steam. Due to high radiation temperature at the nozzle outlet the major fraction of volatiles get escape immediately after entering the 
gasifier and involve in steam gasification as shown in Fig. 10. All the carbonaceous material become steam gasified and remaining ash is used to constitute mass balance. The heat is transferred to particle by two ways: through direct interaction with radiation and; by convective heat transfer from the surrounding steam. The steam enters at $423^{\circ} \mathrm{K}$ interact the incoming radiation and also with the already heated up wall of the reactor. This quickly increases the temperature of the reactor. The average temperature of the reactor is found to be $1,200^{\circ} \mathrm{K}$, which is a suitable temperature to obtain a high quality synthetic gas [16]. The incoming coal particles also interact with the incoming radiation which ultimately increases the temperature of particle, as shown in Fig. 11. The high reactor temperature ensures the quick release of volatiles from coal which rapidly reacts with steam, thereby reducing the mole fraction of volatiles almost to nil near the axis of symmetry.

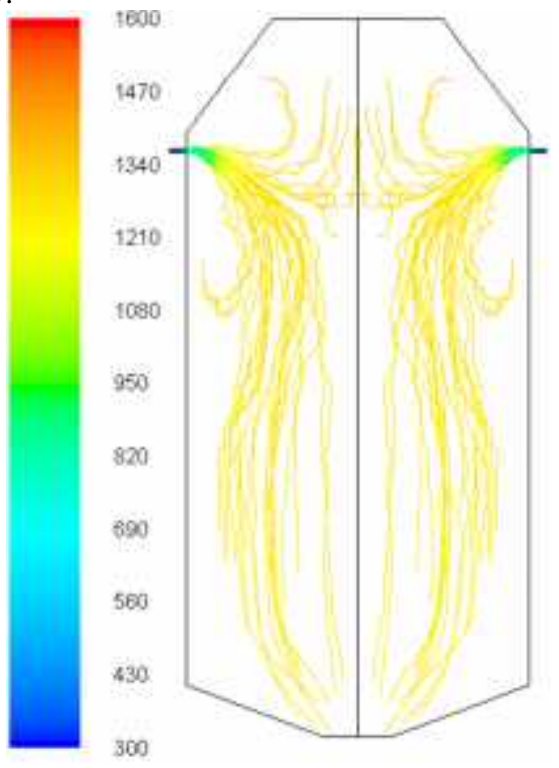

Fig. 11: Contours of static temperature $(\mathbf{K})$

Composition of product synthetic gas is shown in Table 5 . These results shows a similar trend, as reported by literature [9], in terms of mole fraction of product synthetic gas.

Also, it is in line with the trend of the computed systematic analysis; higher mole fraction of $\mathrm{H}_{2}$ than $\mathrm{CO}$ and near zero mole fraction of $\mathrm{CH}_{4}$. The $\mathrm{H}_{2}: \mathrm{CO}$ ratio is found to be 1.45 . As the steam is act as carrier to the coal particles, a surplus amount than actual stoichiometric is required to achieve optimal process efficiency.

Table 5: Mole fraction of product synthetic gas

\begin{tabular}{|l|l|}
\hline Species & $\begin{array}{l}\text { Mole Fraction } \\
\text { CFD }\end{array}$ \\
\hline Volatiles & 0.001 \\
\hline $\mathrm{H}_{2}$ & 0.32 \\
\hline $\mathrm{CO}$ & 0.22 \\
\hline $\mathrm{CO}_{2}$ & 0 \\
\hline $\mathrm{CH}_{4}$ & 0 \\
\hline $\mathrm{H}_{2} \mathrm{O}$ & 0.009 \\
\hline $\mathrm{N}_{2}$ & 0.44 \\
\hline Total & $\sim 1$ \\
\hline
\end{tabular}

To determine the efficiency of gasification process, the cold gas efficiency (CGE) is calculated. CGE is defined as the ratio of heating value of the product gas to that of the virgin feedstock.

$C G E=\frac{H H V_{\text {product gas }}}{H H V_{\text {feedstack }}+\text { Solar energy }}$

Using the HHV of feedstock from literature [14] and the solar energy is taken as the energy of solar radiation incident inside the gasifier. The computed CGE is found to be $90 \%$. This efficiency is significant as compare to the conventional gasification efficiency of coal that ranges from $70-80 \%$. The reason is because almost all the feedstock is converted into syngas by avoiding the partial combustion due to the energy provided via solar radiations.

\section{Conclusion}

The principle of simulating the optics for solar gasifier is to design the system to effectively capture the incident solar radiation for the gasifier. The main benefit of optical modeling is to obtain the physical dimension of the optical system and also the losses due to diffusion and re-radiation form reflectors and gasifier, respectively. Leading to more accurate predictive gasification process. In this work the Hybrid solar endothermic reactor is simulated using coal as feedstock. The result of proximate analysis, ultimate analysis and bomb calorimeter is used to simulate the coal steam gasification. An axi-symmetric geometry fitted with discretized a structure grid is used to carry out the numerical simulation of the reactor. An appropriate nozzle diameter is used to inject coal and steam. The solar radiation is projected inside the reactor using an optical window. The incoming radiation is used to provide an appropriate temperature for gasification. The mixture of coal and steam reacted together in the gasifier to produce syngas. Then nitrogen gas is also used to carry the coal particle in the reactor. Finally, the CGE is calculated, which is found to be $90 \%$ showing the upgraded heating value of product gases by virtue of direct solar irradiation.

\section{References}

1. Rubin, E., A. Rao, and C. Chen. Comparative assessments of fossil fuel power plants with $\mathrm{CO} 2$ capture and storage. 2005

2. Craig, K. and M. Mann, Cost and performance analysis of biomass-based integrated gasification combined-cycle (BIGCC) power systems. NREL, Golden (Colorado), 1996.

3. Zedtwitz, J. Petrasch a, D. Trommer a, A. Steinfeld, Hydrogen production via the solar thermal decarbonization of fossil fuels. Solar Energy, 2006. 80(10): p. 1333-1337.

4. Zedtwitz, P.v. and A. Steinfeld, The solar thermal gasification of coal -- energy conversion efficiency and CO2 mitigation potential. Energy, 2003. 28(5): 441-456.

5. von Zedtwitz, P. and A. Steinfeld, Steam-Gasification of Coal in a Fluidized-Bed/Packed-Bed Reactor Exposed to Concentrated Thermal RadiationModeling and Experimental Validation. Ind. Eng. Chem. Res, 2005. 44(11): p. 3852-3861.

6. Piatkowski, N. and A. Steinfeld, Solar gasification of carbonaceous waste feedstocks in a packed bed reactor- 
Dynamic modeling and experimental validation. AIChE Journal.

7. Piatkowski, N. and A. Steinfeld, Reaction kinetics of the combined pyrolysis and steam-gasification of carbonaceous waste materials. Fuel, 2010. 89(5): p. 11331140 .

8. Z'Graggen, A. and A. Steinfeld, A two-phase reactor model for the steam-gasification of carbonaceous materials under concentrated thermal radiation. Chemical Engineering and Processing: Process Intensification, 2008. 47(4): p. 655-662

9. Z'Graggen, P. Hauetera, D. Trommera, M. Romerob, J.C. de Jesusc, Steinfeld, Hydrogen production by steamgasification of petroleum coke using concentrated solar power--II Reactor design, testing, and modeling. International Journal of Hydrogen Energy, 2006. 31(6): p. 797-811.

10. Z'Graggen, P. Haueter, G. Maag, A. Vidal, A. Steinfeld, Hydrogen production by steam-gasification of petroleum coke using concentrated solar power--III. Reactor experimentation with slurry feeding. International Journal of Hydrogen Energy, 2007. 32(8): p. 992-996.

11. Pitz-Paal, R., N.B. Botero, and A. Steinfeld, Heliostat field layout optimization for high-temperature solar thermochemical processing. Solar Energy, 2011. 85(2): p. 334-343.

12. Pitz-Paal, Jurgen, Barbara, Felix, Alain, Ulrich, Aldo Steindfeld, Jacob, Eduardo, Oleg, Development steps for parabolic trough solar power technologies with máximum impact on cost reduction. Journal of Solar Energy Engineering, 2007. 129: p. 371.

13. TracePro, http://www.lambdares.com/software_products/tracepro/.

14. Shabbar Syed, Isam Janajreh, Thermodynamic equilibrium analysis of coal gasification using Gibbs energy minimization method. Energy Conversion and Management, 2011.

15. Shabbar Syed, Rana Qudaih, Ilham Talab, Isam Janajreh, Kinetics of pyrolysis and combustion of oil shale sample from thermogravimetric data, Fuel, Volume 90, Issue 4, April 2011, Pages 1631-1637, ISSN 0016-2361

16. M. J. Bockelie, M. K. Denison, Z. Chen, T. Linjewile, C. L. Sensior, A. F. Sarofim, "CFD Modeling of Entrained Flow Gasifiers in Version 21 Systems", Report reaction Engineering International, 77 West 200 south, suite 210, Salt Lake City, UT 84101 